\title{
How we see electronic games
}

Andrew K Przybylski, Netta Weinstein

Theories regarding the influences of electronic games drive scientific study, popular debate, and public policy. The fractious interchanges among parents, pundits, and scholars hint at the rich phenomenological and psychological dynamics that underlie how people view digital technologies such as games. The current research applied Martin Heidegger's concept of interpretive frameworks (Heidegger, 1987) and Robert Zajonc's exposureattitude hypothesis (Zajonc, 1968) to explore how attitudes towards technologies such as electronic games arise. Three studies drew on representative cohorts of American and British adults and evaluated how direct and indirect experiences with games shape how they are seen. Results indicated this approach was fruitful: Negative attitudes and beliefs linking games to real-world violence were prominent among those with little direct exposure to electronic gaming contexts, whereas those who played games and reported doing so with their children tended to evaluated gaming more positively. Further findings indicated direct experience tended to inform the accuracy of beliefs about the effects of digital technology, as those who had played were more likely to believe that which is empirically known about game effects. Results are discussed with respect to ongoing debates regarding gaming and broader applications of this approach to understand the psychological dynamics of adapting to technological advances. 
15 Andrew K. Przybylski ${ }^{1 *}$, Netta Weinstein ${ }^{2}$

$17{ }^{1}$ Oxford Internet Institute, University of Oxford, Oxford, United Kingdom

$18{ }^{2}$ School of Psychology, University of Cardiff, Cardiff, United Kingdom

19

$20 *$ Corresponding author

21 E-mail: andy.przybylski@oii.ox.ac.uk 


\section{How We See Electronic Games}

\section{Abstract}

26 Theories regarding the influences of electronic games drive scientific study, popular debate, and 27 public policy. The fractious interchanges among parents, pundits, and scholars hint at the rich

28 phenomenological and psychological dynamics that underlie how people view digital technologies such as games. The current research applied Martin Heidegger's concept of interpretive frameworks (Heidegger, 1987) and Robert Zajonc's exposure-attitude hypothesis

31 (Zajonc, 1968) to explore how attitudes towards technologies such as electronic games arise.

32 Three studies drew on representative cohorts of American and British adults and evaluated how

33 direct and indirect experiences with games shape how they are seen. Results indicated this

34 approach was fruitful: Negative attitudes and beliefs linking games to real-world violence were

35 prominent among those with little direct exposure to electronic gaming contexts, whereas those 36 who played games and reported doing so with their children tended to evaluated gaming more

37 positively. Further findings indicated direct experience tended to inform the accuracy of beliefs

38 about the effects of digital technology, as those who had played were more likely to believe that

39 which is empirically known about game effects. Results are discussed with respect to ongoing

40 debates regarding gaming and broader applications of this approach to understand the

41 psychological dynamics of adapting to technological advances. 


\section{How We See Electronic Games}

46
Anything that is in the world when you're born is normal and ordinary and is just a natural part of the way the world works. Anything that's invented between when you're fifteen and thirty-five is new and exciting and revolutionary and you can probably get a career in it. Anything invented after you're thirty-five is against the natural order of things. (Adams, 2002)

\section{Introduction}

Electronic games are now a dominant entertainment technology (Lenhart, et al., 2015). In the span of a generation, electronic gaming has transitioned from a niche activity available to those with access to university mainframes to a widely pursued form of leisure pursued on a range of devices ranging from smartphones to virtual reality headsets (Parkin, 2013). Half of households in many developed countries now have gaming consoles and it has been estimated hundreds of millions of hours are now invested in gaming each week (Dutton \& Blank, 2013; McGonigal, 2011). This explosion of interest has driven discussions in popular, political, and academic circles regarding the impact technologies such as games could be having on individuals and on society more broadly.

Indeed, many have heralded the potential cognitive, social, and health benefits of game technology (Baranowski, et al., 2008; Wellcome Trust, 2013), whereas others have speculated that they are a contributing cause of mass-shooting tragedies, and advocate for legislation to limit their availability (Brown v. EMA, 2011; Bushman, 2013; Coperhaver, 2014; Dillio, 2014).

Taken as a whole, evidence regarding the effects of electronic games suggests their influence on players - for good or for ill - is small and inconsistent (Anderson et al, 2010; Elson \& Ferguson, 
67 2013; Etchells, Gage, Rutherford, \& Munafò, 2016; Przybylski, 2014a; Sherry, 2001). Though

68 negative effects are estimated to be modest by both critical researchers (e.g., Elson \& Ferguson,

69 2013) and advocates for increased regulation (e.g., Bushman, 2013), there remain many have

70 who have polarized attitudes regarding the place of electronic games in society (for a review see

71 Etchells \& Chambers, 2014). The processes undergirding such polarizations, given the absence

72 of evidence for strong positive or negative influences, are not understood.

73 This gap in our empirical knowledge is an important one because legislative priorities,

74 parenting decisions, and the scientific study of electronic games may be being shaped by

75 attitudinal dynamics we do not yet understand. The aim of the present work is to study views of

76 electronic games using an approach that capitalizes on philosophical and psychological theory.

77 By doing so, the study aims to build empirically grounded insights concerning the conflicting

78 narratives many have with respect to the influences of electronic games.

\section{Philosophical Approaches}

In describing the idea of interpretive frameworks - the ways by which people acquire, systematize, and act on their knowledge - the philosopher and phenomenologist Martin

82 Heidegger (1987) posited that both direct and indirect experience plays fundamental roles in

83 guiding attitudes and beliefs. For Heidegger, both first- and second-hand experience shape

84 internal accuracy - the degree to which individuals' beliefs are considered internally valid and consistent. Only first-hand experience informs what he termed empirical or provisional accuracy

- the degree to which individuals' views are concordant and consistent with reality. Said

87 differently, for Heidegger, direct and indirect experiences are as likely to undergird highly subjective attitudes about specific topics, persons, or technologies, but interpretive frameworks grounded in first-hand experience tend towards congruency with objective and externally valid, 
90 assessments. In this way indirect experience may be internally accurate, that is, contribute to

91 one's own opinion, but only direct experiences can contribute to a view or attitude which is

92 objectively accurate.

93 Psychological Approaches

94 Compatible with the phenomenological approach, a long tradition of psychological

95 research has focused on the ways by which experience shapes attitudes and beliefs (James, 1890;

96 Maslow, 1937). Research in this tradition has demonstrated that familiar experiences and stimuli

97 are preferred to the unfamiliar (Zajonc, 1968). This pattern of observations, framed as the

98 exposure-attitude hypothesis and later the mere exposure effect, proposes that that indirect

99 experience, and even more so, direct experience with objects and stimuli reduces instinctive fear

100 reactions to novel stimuli (Bornstein, 1989; Zajonc, 1968). Nearly six decades of research

101 conducted in laboratory and real-world contexts suggest that the salutatory effect of experience

102 on attitudes are most accurately thought of as based in the affective (Harmon-Jones \& Allen,

103 2001) and perceptual (Reber, Winkielman, \& Schwartz, 1998) correlates of repeated exposure.

104 Said differently, people tend to be more positively and less negatively disposed to stimuli insofar

105 as exposure eases the effort required to perceive and process their features (Seamon, Brody, \&

106 Kauff, 1983) and evokes positive affect (Harmon-Jones \& Allen, 2001). Indirect and direct

107 experience do indeed shape what Heidegger termed internal accuracy, but their roles in

108 determining the external validity, or accuracy, of perspectives on attitudinal objects like

109 technologies are not well understood.

\section{How Gaming Technologies are Seen}

111 Preliminary research investigating attitudes about electronic games suggests that a

112 synthesis of these approaches may provide a useful conceptual frame for studying how people 
113 process and weigh information relevant to gaming. Two studies conducted with representative

114 cohorts suggest that older people, those who grew up before the rise of electronic gaming and

115 therefore have less indirect experience, are less likely to have direct experiences with games and

116 they are more likely to believe games are a contributing cause violence in real-world contexts

117 (Harris, 2013; Przybylski, 2014b). This indicates that the degree of exposure to an entertainment

118 technology may, generally speaking, influence the way it is perceived.

119 Studies with convenience samples suggest that mere exposure, on a generational level,

120 might influence how people see gaming technologies. For example, research by Kneer and

121 colleagues shows that those who grew up in a time when games were common are less likely to

122 believe games cause people to act violently, regardless of whether they themselves play games

123 (Kneer, Glock, Beskes, \& Bente, 2012). Further, there is reason to think that cognitive fluency

124 may have an effect, as people tend to overestimate the influence of games if they consider them

125 in the abstract instead of drawing on concrete experience with specific games (Ivory \&

126 Kalyanaraman, 2009).

127 Given that preliminary evidence suggests familiarity and cognitive fluency with

128 electronic games may shape how they are seen, the lens provided by Heidegger (1987) and

129 Zajonc (1968) may provide a framework for advancing our understanding of attitudes towards

130 digital technologies. Indirect experience through being part of a cohort that discusses and makes

131 visible aspects of gaming might reduce negative views, whereas direct experience may reduce

132 negative views and foster external accuracy of the real impact of games on people. Building on

133 this theorizing, in the current work we explore how these general, cohort-level, and specific,

134 individual-level patterns of experience with games relate to the internal and empirical accuracy

135 of beliefs held about these technologies. 


\section{Present Research}

Three studies investigated how exposure to electronic games relates to people's views of

138 gaming technology, drawing on population representative cohorts to gain a broad and externally

139 valid perspective. These studies are first to evaluate the extent to which mere exposure and direct

140 experience may relate to internally consistent views people have about games (Studies $1 \& 2$ ), as

141 well as views that are externally consistent, that is, in line with what is empirically known about

142 the influences of electronic games (Study 3).

\section{Study 1}

144 Study 1 was aimed at investigating how indirect (i.e., cohort-linked) and direct (i.e.,

145 personal) experiences with electronic games shape one's internally accurate attitudes, using data

146 collected from a nationally representative sample of adults living in the United Kingdom.

147 Hypothesis 1 was based on earlier research and predicted that cohorts with less direct exposure

148 to electronic games - older people and women in particular - would tend to see them negatively

149 (Harris, 2013; Przybylski, 2014b). Hypothesis 2 predicted that those having direct experience

150 with games would generally tend to see them more positively. Finally, because direct exposure

151 and personal experience play a central role in both the approaches of Zajonc and Heidegger, we

152 also tested whether direct experience would mediate the relationship between indirect experience

153 and attitudes (Hypothesis 3).

\section{Method}

\section{Participants and Measures}

156 A nationally representative sample of 959 men and 1019 women $\left(M_{\text {age }}=46.89\right.$ years, $S D$

$157=16.54$ years) completed measures as part of their participation in the YouGov United Kingdom

158 panel. Socio-demographic information was derived from panel data and the questions detailed 
159 below were presented at random in HTML format. The research presented minimal risk, and was

160 granted clearance by the ethics committee of the Oxford Internet Institute at the University of

161 Oxford (CUREC/1A).

162 All participants polled for the present research were above 18 years of age and members

163 of the YouGov United Kingdom (Studies 1 \& 3) or US (Study 2) panels. Panel participants

164 completed a double opt-in process and agreed to the YouGov Terms and Conditions (2015) and

165 were contacted as part of their ongoing participation in the YouGov Omnibus. In line with the

166 YouGov Privacy Policy (2015), the investigators did not have access to any uniquely identifying

167 participant information. Participants could contact investigators using by way of email contact at

168 YouGov. No inquiries linked to the present studies were received.

169 Direct game experience. Graded exposure to electronic games was assessed using a

170 single self-report item that asked participants: "How often, if at all, do you play video / computer

171 games?" This question was paired with a 6-point Likert-style scale that 1,941 participants used to

172 respond: 1 = "most days," 2 = "once a week," 3 = "once a month," 4 = "several times a year," 5=

173 "once a year," 6 = "never." Scores were reverse coded so that high scores reflected higher levels

174 of direct game experience (Table 1 presents the frequency of these different levels of experience

175 for all three studies).

176 Attitudes about games. Attitudes towards video and computer games were measured

177 with participant responses to eight statements about electronic games. Participants were asked to

178 rate the extent to which they agreed or disagreed with eight statements such as "They are a waste

179 of time," and "They are a good form of entertainment." These question were paired with a 5-

180 point Likert-style response scale ranging from: $1=$ "strongly disagree," to $5=$ "strongly agree."

181 Principle components analysis with a Varimax rotation of the data showed two attitude factors 
182 (see Appendix A): A four-item negative attitudes factor accounting for $32.77 \%$ of observed

183 variance, and a four-item positive attitudes factor accounting for $30.64 \%$ of variance. Items were

184 averaged to create a positive attitude score $(M=3.12, S D=0.81, \alpha=.78)$ and a negative attitude

185 score $(M=3.17, S D=0.93, \alpha=.81)$ for each participant.

\section{Results}

\section{Preliminary Analyses}

In line with Hypothesis 1, results from zero-order bivariate analyses indicated that

younger people tended to report more regular experience with games, $r=-.25, p<.001$, and

190 lower negative attitudes, $r=.27, p<.001$, as well as higher levels of positive attitudes, $r=-.22$,

$191 p<.001$, towards games. Although results are identical using either method, point-biserial

192 correlations were used in place of independent samples t-tests to aid the comparison of

193 preliminary statistics. Results from these correlations indicated women tended to have less

194 gaming experience, $r=-.12, p<.001$, and higher negative attitudes, $r=.19, p<.001$, as well as

195 less positive attitudes, $r=-.08, p=.001$, towards games. The results from these preliminary

196 correlation analyses lend preliminary weight to the exposure-attitude hypothesis (Hypothesis 1)

197 with respect to games (see Table 2).

\section{Direct Effects on Gaming Attitudes}

To test the expectation that those who have direct experience or exposure to games would see these technologies more positively (our Hypothesis 2), a regression model was tested holding variability in participant age and gender constant. Evidence revealed direct experience accounted

202 for independent and significant variability $\left(\Delta R^{2}=.10\right)$ in positive views of gaming over and

203 above variance linked to participant age and gender, $\beta=.32, p<.001$. A second regression

204 model found that controlling for participant age and gender, direct game experience was linked 
205 to lower negative attitudes, $\beta=-.32, p<.001$. This result supported that hypothesis, indicating

206 both are significant correlates in their own right, which account for incremental variance $\left(\Delta R^{2}=\right.$

207.09 to .10$)$ beyond socio-demographic cohort factors background.

\section{Indirect Effects on Gaming Attitudes}

A series of models evaluated the indirect effects of cohort-level factors on attitudes

toward games to test Hypothesis 3 (see Figure 1). Results from these models using an asymptotic

211 bootstrapping approach with 1,000 resamples (Preacher \& Hayes, 2008) indicated that

212 participant age and gender had indirect effects on the extent to which they saw games positively

213 by way of personal exposure with gaming contexts (Table 3, top panel). Young people and men

214 tended to have more experience with games and this differential exposure, in turn, related to

215 more positive views of games, a pattern which accounted for between $12.6 \%$ and $14.6 \%$ of

216 observed variability in positive perceptions of games. Models evaluating the indirect effect of

217 age and gender on negative views of games showed that direct exposure to games mediated the

218 links between participants' backgrounds and attitudes (Table 3, bottom panel). Older participants

219 and women tended to have less experience with games and this lack of experience, in turn,

220 related to more negative views as these indirect associations $\left(\Delta R^{2}\right)$, accounting for between

$221 \quad 15.7 \%$ and $17.2 \%$ of variability in negative attitudes towards games.

Brief Discussion

Findings from this study provided support for applying the psychological and

224 philosophical approaches of Zajonc and Heidegger to understanding attitudes towards gaming 225 technologies. However, in this study attitudes were examined broadly as positive and negative evaluations of technology use. Study 2 was designed to test if these findings generalized to a separate sample, and to increase the scope of the research by testing more policy-relevant views 
228 on whether games are causally linked to mass-shooting events (e.g., Bushman, 2013), and

229 whether laws are needed to restrict access to games (Brown v. EMA, 2011). We once again

230 tested the three hypotheses from Study 1: that indirect exposure would link with more positive

231 attitudes (Hypothesis 1), as would direct exposure (Hypothesis 2), and that direct exposure

232 would mediate the effects with indirect exposure (Hypothesis 3).

\section{Study 2}

\section{Methods}

235

236

237

\section{Participants and Measures}

A nationally representative US sample of 483 men and 517 women $\left(M_{\text {age }}=48.39\right.$ years, $S D=16.83$ years) completed the study measures as part of their participation in the YouGov United States panel. Just as was the case in Study 1, socio-demographic cohort-level variables were collected as part of panel participation and measures of direct game experience were unchanged from the first study. A total of 961 participants $(96 \%)$ responded about their gaming experience.

Attitudes about games. Internally valid attitudes towards video and computer games were measured with participant responses to four attitudinal items regarding electronic games (see Appendix B), similar to Study 1. Principle components analysis showed these four items loaded on a single factor, accounting for $54.48 \%$ of observed item variance. Responses to the negatively worded items were reverse coded and averaged with the positive ones to create a single measure of positive attitudes regarding gaming score $(M=3.29, S D=.78, \alpha=.70)$.

Games in society. Two single-item measures were used to assess participants' policyrelevant beliefs concerning electronic games. The first item concerned games and mass violence: "Video/computer games are a contributing cause in mass-shootings", and the second focused on 
251 legal regulation of gaming: "New legislation is needed to restrict the availability of

252 video/computer games." Participants used the same 5-point Likert-style scale utilized for general

253 attitude items. A total of 932 participants responded to the item assessing a gaming-shooting link

$254(M=2.66, S D=1.26)$ and 950 participants responded to the question regarding new gaming

255 legislation with the same 5-point response scale used to assess gaming attitudes $(M=2.40, S D=$ 256 1.22).

Results

258

259

260

261

262

263

264

265

266

267

268

269

270

271

272

273

\section{Preliminary Analyses}

Results from zero-order correlation analyses indicated that socio-demographic

background factors related to views of games in line with the exposure-attitude hypothesis (Hypothesis 1; Table 4). Older adults tended to report less regular exposure to games, $r=-.16, p$ $<.001$, and less positive attitudes towards games, $r=-.27, p<.001$. Older people were more likely to believe that gaming was linked to mass shootings, $r=.23, p<.001$, and that laws were needed to restrict games, $r=.19, p<.001$. Participant gender showed a similar albeit weaker set of associations indicating that women held less positive attitudes, $r=-.08, p=.010$, and were more likely to think games cause shootings, $r=.10, p=.002$, and favor laws to limit games, $r=$ $.15, p<.001$.

\section{Direct Effects on General Attitudes and Gaming Policy}

A hierarchical regression model tested the hypothesis that games would evoke generally positive reactions in those who have had previous experience with them (Hypothesis 2). Positive attitudes about gaming were regressed onto gaming experience, $\beta=.37, p<.001$, which accounted for $13.5 \%\left(\Delta R^{2}\right)$ of variability in this construct over and above participant age, gender, and parenting status. These findings conceptually replicated the findings of Study 1. 

viewing electronic games is linked to lower likelihood of believing they play a contributing role

276 in mass-shooting or favoring new laws to regulating game availability. Results from these

277 models showed that direct gaming experience was negatively linked to both thinking they contribute to mass-shootings, $\beta=-.15, p<.001, \Delta R^{2}=.02$, and that new laws are needed, $\beta=-$ $.10, p=.002, \Delta R^{2}=.01$, holding variability in participant age and gender constant.

\section{0}

\section{Indirect Effects on General Attitudes and Gaming Policy}

A series of analyses examined the indirect effects of age and gender on outcomes of interest using the asymptotic boot-strapping approach employed in Study 1 (Hypothesis 3). Models examining general attitudes about games, beliefs about games and mass-shootings, and thinking new laws are needed to restrict games are presented in Table 5. Results indicated that there were significant indirect links for age to general attitudes by way of direct experience $\left(R^{2}=\right.$ .18), but no indirect effect was observed for gender (top panel). Direct experience mediated relations linking age $\left(R^{2}=.06\right)$ and gender $\left(R^{2}=.03\right)$ to the belief that video game play contributes to mass-shootings (middle panel). A similar pattern of indirect effects was observed for favoring new restrictive legislation with direct experience mediating links for age $\left(R^{2}=.04\right)$, but no indirect effect was in evidence for participant gender (bottom panel).

\section{Brief Discussion}

Findings from this study conceptually replicated and extended the findings from the first study to an American sample and focused on key attitudes driving policy. This is particularly important as it indicates specific, internally held views, on matters of legal policy towards technology may be shaped, in part on the extent to which members of the general public have direct and indirect experience with the technology in question. 
The purpose of Study 3 was to go further and investigate the accuracy of perceptions of

298

299

300

301

302

303

304

305

306

307

308

309

310

311

312

313

314

315

316

317

318

319

gaming technology. Although research investigating the influence of games is ongoing (see

Elson \& Ferguson, 2014), researchers largely agree that both the positive and negative effects are small (Greitmeyer \& Mügge, 2014; Hull, Brunelle, Prescott, \& Sargent 2014; Przybylski, 2014b), depend on a range of contextual moderators (Sherry, 2001), and may not be reliable (van Ravenzwaaij, Boekel, Forstmann, Ratcliff, \& Wagenmakers, 2014). Given these available estimates, this study treated these conclusions from the literature as the ground truth in terms of the Heideggerian concept of empirical accuracy. Following from this, four predictions focused on the empirical accuracy of people's beliefs based on Zajonc's and Heidegger's perspectives were tested.

Hypothesis 1: First, in line with the mere exposure effect and results from Studies 1 and 2 indicating that older participants and women tended to have less direct game experience, it was hypothesized that members of these cohorts would evaluate game effects more negatively and less positively than would be suggested by the scientific literature.

Hypothesis 2: Second, in line with Zajonc and Heidegger, it was predicted that those with direct personal experience of games - in this case, players and caregivers who co-play with their children - would be more likely to hold positive and empirically accurate views. Specifically, it was hypothesized they would be more likely to believe games have small and inconsistent positive and negative effects - a position well-supported by scientific evidence - because their views are, in aggregate, based in actual experience.

Hypothesis 3: Finally, in line with Heidegger's interpretive frameworks, we hypothesized that first hand experience with games would mediate any links between cohort membership and the empirical accuracy of individuals' evaluations of electronic game effects. 


\section{Study 3}

321

\section{Method}

\section{Participants and Measures}

323

324

325

326

327

328

330

331

332

A nationally representative UK sample of 929 men and 987 women $\left(M_{\text {age }}=46.87, S D=\right.$ 16.44) completed the study measures as part of their participation in the YouGov United Kingdom panel. The measure of direct gaming experience $(1,869$ responses $)$ was the same as in Studies 1 and 2 (see Table 1). New to Study 3 were measures of caregiver status, caregiver-child co-play, and individual evaluations of positive and negative game effects.

Caregiver-child co-play. Participants who were caregivers for a young person aged 18 or younger were asked if they play video/computer games with their child/children. A total of 426 participants (or $22.2 \%$ ) identified as caregivers, and 211 of these (or $49.5 \%$ ) reported playing with their child.

Positive influences of gaming. Because literatures considering salutatory (Baranowski, et al., 2008) and negative effects (Anderson et al, 2010) are distinct, participants were asked separately about positive and negative influences of gaming. Judgment regarding the potential positive influences of electronic games on young people was assessed with a single item that asked participants to reflect on their beliefs regarding video and computer games. This question was paired with four response options: $1=$ "Games have large and significant POSITIVE effects on young people," 2 = "Games have small and inconsistent POSITIVE effects on young people," $3=$ "Games have no POSITIVE effects on young people," or 4 = "I don’t know." A total of 1,916 participants responded to this item; $13.9 \%$ stated they have a large positive effect, $30.1 \%$ believed they had no positive effects, and $21.9 \%$ said they did not know. Roughly one third of 
342 the sample, $34.1 \%$, endorsed an empirically valid response by stating they think games may have

343 small and inconsistent positive effects.

344 Negative influences of gaming. Participants were asked to reflect on their beliefs

345 regarding video and computer games and were provided with four response option: $1=$ "Games

346 have large and significant NEGATIVE effects on young people," 2 = "Games have small and

347 inconsistent NEGATIVE effects on young people," 3 = "Games have no NEGATIVE effects on

348 young people," or 4 = "I don't know." A total of 1,916 participants responded to this item;

$34925.1 \%$ stated games have large negative effects, $8.9 \%$ believed gaming has no negative effects,

350 and $22.3 \%$ said they did not know. Just under half of participants, or $43.7 \%$, provided an

351 empirically accurately estimation by stating they believe games may have small and inconsistent

352 negative effects.

Results

\section{Preliminary Analyses}

Results from zero-order correlation analyses indicated that younger adults tended to report more personal experience with games, $r=-.23 p<.001$. Women were less likely to coplay games with their children than men, $r=-.12, p<.001$, and to report direct experience with games $r=-.10, p<.001$. Those who had direct experience with games were also more likely to co-play with their children, $r=.71, p<.001$.

Analytic Approach

A series of multinomial logistic regression models examined the effects of indirect and

362 direct experience with interactive gaming technology on holding high, low, and empirically-

363 accurately estimates of the impact of electronic games on young people. This approach

364 minimized the number of statistical tests required and allowed each model to estimate the extent 
365 to which different person-level factors would be associated with judgments. Table 7 shows

366 effects for judgments about the nature of positive effects of gaming, and Table 8 shows the

367 judgments concerning the potential negative effects. A series of targeted models evaluated the

368 indirect effects on empirically accurate estimations (Table 9), following the approach used in

369 Studies 1 and 2. These logistic mediation models used a coding of 1 for those who provided an

370 empirically accurate estimate of probable game effects on young people (i.e., small and

371 inconsistent) and 0 for those who provided any other estimate (e.g., large and significant positive

372 effect). These mediation models examined the indirect effects of direct gaming experience on

373 evaluations of gaming technology.

374 Direct Effects on High Estimation of Effects

375 Models examining correlates of estimating large positive effects of gaming indicated co-

376 playing caregivers were slightly more likely (1.13x) than non co-playing parents to think that

377 games have large positive effects on young people. Similar results were found for those who

378 engage games frequently. Compared to individuals without personal experiences playing games,

379 those who played games on a daily $(2.97 \mathrm{x})$ and weekly basis $(4.14 \mathrm{x})$ tended to be more likely to

380 think games have large positive effects. Multinomial models also showed three groups tended to

381 estimate large negative effects. Compared to men, women were almost twice as likely (1.79x) to

382 report belief in large negative effects of games on young people. Those who played games a few

383 times a year $(2.13 \mathrm{x})$ were also more likely to believe that technology has a large negative effect

384 on young people.

\section{Direct Effects on Low Estimation of Effects}

386 Results showed that those who played games several times each year were the only

387 cohort that estimated no positive gaming effects to a significantly greater extent, being 1.75 
388 times more likely to have a lower estimate compared to those who have never played games.

389 Results indicated a number of groups tended to underestimate the potential negative effects of

390 electronic gaming on young people. Men were twice as less likely $(2.18 \mathrm{x})$ as women to believe

391 games have no negative effects. Caregivers who played games with their kids, compared to those

392 who did not, were also more 2.63 times less likely to believe that games had no negative effects.

393 Compared to those who never played games, those who played on daily (2.81x), weekly (2.43x),

394 and monthly (3.56x) basis were more likely to provide lower estimates of the potential negative

395 effects of games than scientific evidence would suggest.

396 Direct Effects on Empirically-Accurate Estimation of Effects

397 Importantly, participants varied significantly in terms of their accurate knowledge of

398 gaming effects. Results demonstrated that men were more likely (1.42x) than women to believe

399 games had small and inconsistent positive effects, a belief in line with what is empirically known

400 about their positive effects. This was also the case for caregivers, who were more likely (1.41x)

401 to be accurate compared to their non-caregiving peers. Parents who played with their children

402 were a further three times (3.03x) more likely, compared to non co-play caregivers, to accurately

403 estimate the magnitude of their positive influence. Direct gaming experience also showed strong

404 effects as participants who played games on daily (2.56x), weekly (3.61x), and monthly (2.41x)

405 basis or several times a year (1.74x) were more likely to correctly estimate the actual size of

406 potential positive effects of gaming on young people compared to those who reported no

407 experience with games.

408 Also importantly, a number of socio-demographic cohorts demonstrated they have a firm

409 handle on the size of the negative effects that electronic games might have on young people.

410 Caregivers in general, and caregivers who play with their children specifically, were more likely 
411 to have an accurate idea of their negative effects (1.39x and 2.78x, respectively). Results also

412 showed that personal experience with electronic games was important. Further, those who played

413 electronic games on daily (2.81x), weekly (2.43x), and monthly basis (3.56x), were more likely

414 to correctly estimate the negative effects of gaming compared to those with no direct experience

415 to draw on.

416 Indirect Effects on Empirically-Accurate Estimation of Effects

417 A series of tests examined direct game experience as a mediator linking age, gender,

418 caregiver status and caregiver-child co-play to reporting empirically-accurate evaluations of the

419 extent to which, for good or ill, gaming contexts shape young people. This approach closely

420 followed the analytic technique used in Studies 1 and 2 to examine gaming attitudes. Though,

421 because the outcome variables were dichotomous (i.e., inaccurate $=0$ vs. accurate $=1$ ), the

422 proportion reduction in error estimates reported are Nagelkerke $R^{2}$ values in place of adjusted $R^{2}$.

423 Indirect effects models (Table 9) indicated that direct gaming experience mediated the

424 links between age, gender, and caregiver status, accounting for approximately 5\% of accuracy.

425 Although the direct effect linking caregiver co-play to accuracy regarding the positive effects of

426 gaming was significant, there was no evidence for mediation by way of direct personal

427 experience for these models. Models examining the accuracy of negative gaming effects on

428 young people showed that both forms of experience with gaming contexts served as mediators

429 linking indirect exposure to this outcome. These indirect effects models accounted for roughly

$4305 \%$ of variability in correctly identifying scientifically verifiable negative effects of gaming.

\section{Discussion}

433 these attitudes guide the choices made by caregivers, educators, policy-makers, and researchers. 
434 Guided by the exposure-attitude hypothesis (Zajonc, 1968), the present research synthesized and

435 examined a subset of the promising factors that may guide how people judge the place of games

436 in society. Broadly speaking, the findings derived across three nationally representative samples

$437\left(n_{\text {tot }}=4,894\right)$ lent support to the view that perceptions of these entertainment mediums vary

438 systematically across the population as a function of both socio-demographic factors such as age

439 as well as exposure and experience with gaming technologies.

$440 \quad$ Findings from Studies 1 and 2 suggested that background factors associated with less

441 exposure to electronic games were related to negative attitudes toward games, whereas those able

442 to draw on direct experience with these technologies tended towards skepticism with regards to

443 real-world violence and legislative efforts to restrict the availability of games. Results from

444 mediation analyses indicated both backgrounds and personal experiences were linked to

445 perspectives on gaming across large nationally representative cohorts. This pattern of findings

446 links existing work focused on games to social psychological theorizing on the role of mere-

447 exposure, finding support that those exposed to technology perceive it to be a less negative or

448 potentially harmful influence on individuals, and extends this view in differentiating indirect and

449 direct experiences. Indeed, interpreting these data, it may be that individuals have different

450 opportunities or desires to engage and experience technology as a function of their backgrounds;

451 for example, those who are older were less likely to grow up with easy access to technology.

452 Findings from Study 3 speak to the challenges faced by parents and those who play

453 electronic games. A number of findings expected by the mere exposure effect were in evidence

454 and speak to the heated debates in the public, academic, and policy arenas. First, most

455 importantly, those we expect might be motivated to ascertain accurate information about the

456 effects of games were also the most likely to correctly estimate their influence on young people. 
457 Compared to their non-parent peers, both co-playing and non co-playing caregivers were more

458 accurate in their beliefs regarding gaming effects. A similar pattern was in evidence for adults

459 conversant in the world of gaming; those who were exposed to gaming stimuli on daily, weekly,

460 and monthly bases were the most likely to accurately estimate the magnitude of both the positive

461 and negative effects observed in scientific studies of this technology. Second, as a note of

462 caution, findings suggested some individuals who had direct experience with games were more

463 liable to overestimate the positive and underestimate the possible negative impact of games on

464 young people, whereas the opposite error was observed in those with little gaming experience.

465 These broad tendencies to see games in a biased way - one not grounded in scientific evidence -

466 should be carefully considered by those producing, studying, and crafting regulations concerned

467 with these digital technologies.

468 These studies speak to how attitudes around technology use are formed, and may guide

469 future work in the area which examines behavior linked to technology use. Social scientists have

470 long known that attitudes shape behavior, but in sometimes complicated or inconsistent ways

471 (e.g., Fishbein, 1966). In future work, researchers could examine how holding the attitudes

472 measured in this study in turn influence which policy decisions are made, and the extent parents

473 and other caregivers support or monitor children's technology use. Indeed, it would be useful to

474 examine how both exposure and pre-existing attitudes toward technology use influence the ways

475 people understand new research findings regarding the effects of technology use on children.

476 Research Limitations and Future Directions

477 Though informative, these studies present two limitations that bear mention. First and

478 foremost, the present studies used cross-sectional data, and as such no causal inferences may be

479 drawn. Indeed, given the nature of the data it is possible that attitudes shape game exposure, not 
480 the reverse. Future work tracking engagement with and public opinion regarding interactive

481 technologies, using either a prospective design or selective exposure in a laboratory experiment,

482 both of which would be highly informative. Second, though the pattern of results observed across

483 studies was relatively consistent, the magnitude of these relations were modest, accounting for

484 roughly 4 to 20 percent of variance in people's views. It is likely that measures drafted to tap a

485 wider range of gaming experiences sensitive to individuals' history of gaming and preferences

486 would account for more predictive variance in popular attitudes. For example, it would be

487 worthwhile in future research to explore how both quantity and quality (for example, which

488 games people play) of direct experience links to attitudes, and the importance of exposure

489 relative to cultural (e.g., socio-political) and informational (e.g. news sources) factors. Knowing

490 how long people have been playing games, and what kinds of games they have in mind when

491 considering their effects would be greatly informative. As it stands, the present work provides a

492 robust starting point for continued research investigating how cohort- and person-level factors

493 are linked to the attitudes held regarding electronic games.

\section{Closing Remarks}

495 As Douglas Adams observed, technologies are often taken for granted by those who grow 496 up them and are viewed less favorably by those who have little experience with them (Adams,

497 2002). Given that psychological scientists are actively studying how technologies such as social

498 media and electronic games may influence cognition (van Ravenzwaaij et al., 2014), emotion

499 (Przybylski, Rigby, \& Ryan, 2010), and aggression (Elson \& Ferguson, 2013), an empirically

500 grounded understanding of studies and preconceptions about interactive technologies is critical.

501 This work argues and demonstrates that an approach theoretically and empirically grounded in 
502 psychological (Zajonc, 1968) and philosophical (Heidegger, 1987) perspectives provides a

503 fruitful avenue for understanding the place of electronic games in science, society, and policy. 
505

506

507

508

509

510

511

512

513

514

515

516

517

518

519

520

521

522

523

524

525

526

527

528

529

530

531

532

533

534

535

536

537

538

539

\section{References}

Adams D. The Salmon of Doubt: Hitchhiking the Universe One Last Time. New York: Harmony; 2002.

Anderson CA, Shibuya A, Ihori N, Swing EL, Bushman BJ, Sakamoto A, Rothstein HR, Saleem M. Violent video game effects on aggression, empathy, and prosocial behavior in eastern and western countries: a meta-analytic review. Psychol Bull. 2010; doi: $10.1037 / \mathrm{a} 0018251$

Baranowski T, Buday R, Thompson DI, Baranowski J. Playing for real: video games and stories for health-related behavior change. Am J Prev Med. 2008; 10.1016/j.amepre.2007.09.027

Bushman BJ. Do violent video games play a role in shootings? September 13, 2013. Available: http://edition.cnn.com/2013/09/18/opinion/bushman-video-games/

Coperhaver A. Violent video game legislation as pseudo-agenda. Crim Just Stud. 2015; doi: 10.1080/1478601X.2014.966474

Dillio R. A Critical Miss: Video Games, Violence, and Ineffective Legislation. First Am Stud. 2014; doi: 10.1080/21689725.2014.950496

Dutton B, Blank G. Cultures of the Internet: The Internet in Britain. 2015; Available: http://oxis.oii.ox.ac.uk/wp-content/uploads/2014/11/OxIS-2013.pdf

Elson M, Ferguson CJ. Twenty-five years of research on violence in digital games and aggression. Euro Psy. 2013; doi: 10.1027/1016-9040/a000147

Etchells P, Chambers C. Violent video games research: consensus or confusion? October 10, 2014. Available: http://www.theguardian.com/science/headquarters/2014/oct/10/violent-video-games-research-consensus-or-confusion

Etchells, P. J., Gage, S. H., Rutherford, A. D., \& Munafò, M. R. (2016). Prospective Investigation of Video Game Use in Children and Subsequent Conduct Disorder and Depression Using Data from the Avon Longitudinal Study of Parents and Children. PLoS ONE, 11(1), e0147732. http://doi.org/10.1371/journal.pone.0147732

Fishbein M. The relationships between beliefs, attitudes and behavior. In cognitive consistency, motivational antecedents and behavioral consequents, 1966; 199-223.

Greitemeyer T, \& Mügge DO. Video games do affect social outcomes: A meta-analytic review of the effects of violent and prosocial video game play. Pers Soc Psychol Bull. 2014; doi: $10.1177 / 0146167213520459$

Harmon-Jones E, Allen JJ. The Role of Affect in the Mere Exposure Effect: Evidence from Psychophysiological and Individual Differences Approaches. Pers Soc Psychol Bull. 2001;27 889-898 
540 Harris Interactive. Majority of Americans See Connection Between Video Games and Violent

541

542

543

544

545

546

547

548

549

550

551

552

553

554

555

556

557

558

559

560

561

562

563

564

565

566

567

568

569

570

571

572

573

Behavior in Teens. 2013. Available: http://www.harrisinteractive.com/vault/Harris\%20Poll\%2010\%20$\% 20$ Video\%20Games_2\%2027\%2013.pdf

Heidegger M. Being and time. Oxford: Blackwell; 1987.

Hull JG, Brunelle TJ, Prescott AT, Sargent JD. A longitudinal study of risk-glorifying video games and behavioral deviance. J Pers Soc Psychol. 2014; doi: 10.1037/a0036058

Ivory JD, Kalyanaraman S. Video games make people violent-Well, maybe not that game: Effects of content and person abstraction on perceptions of violent video games' effects and support of censorship. Comm Rep 2009; doi: 10.1080/08934210902798536

James W. The principles of psychology (Vol. 2). New York: Holt; 1890.

Kneer J, Glock S, Beskes S, Bente G. Are digital games perceived as fun or danger? Supporting and suppressing different game-related concepts. Cyberpsychol Behav Soc Netw. 2012; doi:10.1089/cyber.2012.0171

Lenhart A, Duggan M, Perrin A, Stepler R, Rainie R, Parker K. Teens, Social Media \& Technology Overview 2015. Pew Internet \& American Life Project. 2015; Available: http://www.pewinternet.org/2015/04/09/teens-social-media-technology-2015

Maslow AH. The influence of familiarization on preference. J Exp Psychol. 1937;21, 162-180.

McGonical, J. Reality is broken. Why Games Make Us Better and How They Can Change the World. Vintage Digital; London; 2011.

Parkin S. New Interfaces Inspire Inventive Computer Games MIT Technology Review. 2013. Available: http://www.technologyreview.com/news/522231/new-interfaces-inspireinventive-computer-games/

Preacher KJ, Hayes AF. Asymptotic and resampling strategies for assessing and comparing indirect effects in multiple mediator models. Beh Res Meth. 2008; 10.3758/BRM.40.3.879

Przybylski AK. Electronic gaming and psychosocial adjustment. Pediatrics. 2014a; doi: 10.1542/peds.2013-402

Przybylski AK. Who believes electronic games cause real world aggression? Cyberpsychol Behav Soc Netw. 2014b; doi: 10.1089/cyber.2013.0245

Przybylski AK, Rigby CS, Ryan RM. A motivational model of video game engagement. Rev Gen Psychol. 2010; doi: 10.1037/a0019440

Reber R. Winkielman P. Schwarz N. Effects of perceptual fluency on affective judgments. Psychol Sci. 1998; 9 45-48. 
574 Seamon, J. G., Brody, N., \& Kauff, D. M. (1983). Affective discrimination of stimuli that are not

575

576

577

578

579

580

581

582

583

584

585

586

587

588

589

590

591

592

593

594 recognized: II. Effect of delay between study and test. Bull Psychon Soc. 1983;21 187189.

Sherry JL. The effects of violent video games on aggression. Hum Comm Res. 2001;

DOI: $10.1111 / \mathrm{j} .1468-2958.2001 . t b 00787 . \mathrm{x}$

Supreme Court of the United States. Brown v. Entertainment Merchants Assn. 2011. Available: http://www.supremecourt.gov/opinions/10pdf/08-1448.pdf

van Ravenzwaaij, D, Boekel W, Forstmann BU, Ratcliff R., Wagenmakers EJ. Action video games do not improve the speed of information processing in simple perceptual tasks. J Exp Psychol Hum. 2014; http://dx.doi.org/10.1037/a0036923

Wellcome Trust. Wellcome Trust Monitor Wave 2: Tracking public views on science, biomedical research and science education. May, 2013. Available:

http://www.wellcome.ac.uk/stellent/groups/corporatesite/@msh_grants/documents/web_ document/wtp053113.pdf

YouGov. YouGov Privacy Policy. 2015. Available: https://yougov.co.uk/about/privacy/

YouGov. YouGov Terms and Conditions. 2015. Available: https://yougov.co.uk/about/termsconditions/

Zajonc RB. Attitudinal effects of mere exposure. J Pers Soc Psychol. 1968; doi: $10.1037 / \mathrm{h} 0025848$ 
Table 1: Frequency of Different Levels of Experience with Electronic Games.

596

\begin{tabular}{|c|c|c|c|c|c|c|c|c|c|}
\hline & \multicolumn{3}{|c|}{ Study 1 (UK) } & \multicolumn{3}{|c|}{ Study 2 (US) } & \multicolumn{3}{|c|}{ Study 3 (UK) } \\
\hline & Total & Men & Women & Total & Men & Women & Total & Men & Women \\
\hline \multicolumn{10}{|l|}{ Direct Game Experience } \\
\hline Never, \% & 46.4 & 40.3 & 52.2 & 30.6 & 30.1 & 31.1 & 45.8 & 39.6 & 51.7 \\
\hline Once a year, $\%$ & 6.6 & 6.7 & 6.5 & 7.0 & 7.8 & 6.2 & 3.9 & 4.2 & 3.6 \\
\hline Several times a year, $\%$ & 9.8 & 10.5 & 9.1 & 11.0 & 11.1 & 10.9 & 9.2 & 10.8 & 7.6 \\
\hline Once a month, $\%$ & 6.2 & 6.2 & 6.2 & 6.3 & 6.1 & 6.4 & 7.8 & 8.8 & 6.8 \\
\hline Once a week, \% & 11.8 & 15.5 & 8.3 & 15.7 & 15.2 & 16.2 & 14.6 & 16.9 & 12.5 \\
\hline Most days, $\%$ & 19.2 & 20.7 & 17.8 & 29.4 & 29.7 & 29.2 & 18.7 & 19.7 & 17.7 \\
\hline
\end{tabular}

597

598 Note. Percentages reflect adjusted valid proportions of adults at different levels of game engagement as weighted by

representativeness across the United Kingdom (Studies 1 and 3) and United States (Study 2). 
601

602

Table 2: Bivariate Correlations Between Observed Variables in Study 1.

\begin{tabular}{lcccc}
\hline & 1. & 2. & 3. & 4. \\
\hline 1. Age & -- & & & \\
2. Gender & .02 & -- & & \\
3. Direct Game Experience & $-.25^{* * *}$ & $-.12^{* * *}$ & -- & \\
4. Negative Attitude About Games & $.27^{* * *}$ & $.19^{* * *}$ & $-.38^{* * *}$ & -- \\
5. Positive Attitude About Games & $-.22^{* * *}$ & $-.08^{* *}$ & $.36^{* * *}$ & $-.45^{* * *}$ \\
\hline
\end{tabular}

603 note: Zero-order correlation coefficients weighted by representativeness of participants across the United Kingdom general 604 population.. $* * * p<.001$ 
607

608Table 3: Study 1 Indirect Effects Analyses Examining Direct Experience as a Mediating Factor

609

\begin{tabular}{|c|c|c|c|c|c|c|c|c|c|c|}
\hline $\begin{array}{c}\text { Dependent } \\
\text { Variable (DV) }\end{array}$ & $\begin{array}{l}\text { Independent } \\
\text { Variable (IV) }\end{array}$ & $\begin{array}{l}\text { Mediating Variable } \\
\text { (MV) }\end{array}$ & $\begin{array}{l}\text { Total Effect } \\
\text { IV to DV }\end{array}$ & $\begin{array}{l}\text { Direct Effect } \\
\text { IV to DV }\end{array}$ & $\begin{array}{l}\text { IV to } \\
\text { MV }\end{array}$ & $\begin{array}{l}\text { MV to } \\
\text { DV }\end{array}$ & $\begin{array}{l}\text { Indirect } \\
\text { Effect }\end{array}$ & \multicolumn{2}{|c|}{$\begin{array}{l}\text { Boot-Strapped Bias Corrected } \\
95 \% \text { C.I. for Indirect Paths }\end{array}$} & $\begin{array}{c}\text { Model } \\
\text { Variance }\end{array}$ \\
\hline $\mathrm{Y}$ & $\mathrm{X}$ & $\mathrm{Z}$ & $\mathrm{c}$ & $\mathrm{c}^{\prime}$ & $\mathrm{a}$ & $\mathrm{b}$ & $a * b$ & Lower Level & Higher Level & $R^{2}$ \\
\hline Positive & Age & Direct Gaming Exp. & -0.012 & -0.008 & -0.029 & 0.126 & -0.004 & -0.005 & -0.003 & .146 \\
\hline Attitudes & Gender & Direct Gaming Exp. & -0.141 & -0.079 & -0.452 & 0.137 & -0.062 & -0.089 & -0.035 & .126 \\
\hline Negative & Age & Direct Gaming Exp. & 0.015 & 0.011 & -0.029 & -0.151 & 0.004 & 0.003 & 0.006 & .172 \\
\hline Attitudes & Gender & Direct Gaming Exp. & 0.323 & 0.248 & -0.457 & -0.164 & 0.075 & 0.044 & 0.109 & .157 \\
\hline
\end{tabular}

610

611 note: Coefficients are shown are non-standardized slopes. Models weighted by representativeness of participants across the United

612 Kingdom general population. 
613 Table 4: Observed Variables in Study 2

\begin{tabular}{lccccc}
\hline & 1. & 2. & 3. & 4 & 5. \\
\hline 1. Age & -- & & & & \\
2. Gender & .03 & -- & & & \\
3. Direct Game Experience & $-.16^{* * *}$ & .01 & -- & & \\
4. Attitude About Games & $-.27^{* * *}$ & $-.08^{*}$ & $.40^{* * *}$ & -- & \\
5. Gaming-Shooting Link & $.23^{* * *}$ & $.10^{* * *}$ & $-.18^{* * *}$ & $-.62^{* * *}$ & -- \\
6. New Gaming Legislation & $.19^{* * *}$ & $.15^{* * *}$ & $-.12^{* * *}$ & $-.49^{* * *}$ & $.64^{* * *}$ \\
\hline
\end{tabular}

614

615 Note. Zero-order correlation coefficients weighted by representativeness of participants across the United States general population.

$616 * * * p<.001, * p<.05$ 


\begin{tabular}{|c|c|c|c|c|c|c|c|c|c|c|}
\hline $\begin{array}{c}\text { Dependent Variable } \\
\text { (DV) }\end{array}$ & $\begin{array}{c}\text { Independent } \\
\text { Variable (IV) }\end{array}$ & $\begin{array}{c}\text { Mediating Variable } \\
\text { (MV) }\end{array}$ & $\begin{array}{l}\text { Total Effect } \\
\text { IV to DV }\end{array}$ & $\begin{array}{l}\text { Direct Effect } \\
\text { IV to DV }\end{array}$ & $\begin{array}{l}\text { IV to } \\
\text { MV }\end{array}$ & $\begin{array}{l}\text { MV to } \\
\text { DV }\end{array}$ & $\begin{array}{c}\text { Indirect } \\
\text { Effect }\end{array}$ & $\begin{array}{r}\text { Boot-Strappe } \\
95 \% \text { C.I. fo } \\
\end{array}$ & $\begin{array}{l}\text { Bias Corrected } \\
\text { ndirect Effect }\end{array}$ & $\begin{array}{c}\text { Model } \\
\text { Variance }\end{array}$ \\
\hline $\mathrm{Y}$ & $\mathrm{X}$ & $\mathrm{Z}$ & $\mathrm{c}$ & $\mathrm{c}^{\prime}$ & $\mathrm{a}$ & $\mathrm{b}$ & $a^{*} b$ & Lower Level & Higher Level & $R^{2}$ \\
\hline $\begin{array}{l}\text { Attitude } \\
\text { About } \\
\text { Games }\end{array}$ & $\begin{array}{l}\text { Age } \\
\text { Gender }\end{array}$ & $\begin{array}{l}\text { Direct Game Exp. } \\
\text { Direct Game Exp. }\end{array}$ & $\begin{array}{l}-0.012 \\
-0.049\end{array}$ & $\begin{array}{l}-0.010 \\
-0.086\end{array}$ & $\begin{array}{r}-0.017 \\
0.258\end{array}$ & $\begin{array}{l}0.133 \\
0.144\end{array}$ & $\begin{array}{r}-0.002 \\
0.037\end{array}$ & $\begin{array}{l}-0.003 \\
-0.005\end{array}$ & $\begin{array}{r}-0.001 \\
0.076\end{array}$ & $\begin{array}{l}.180 \\
\mathrm{n} / \mathrm{a}\end{array}$ \\
\hline $\begin{array}{l}\text { Belief Games } \\
\text { Contribute to } \\
\text { Shootings }\end{array}$ & $\begin{array}{l}\text { Age } \\
\text { Gender }\end{array}$ & $\begin{array}{l}\text { Direct Game Exp. } \\
\text { Direct Game Exp. }\end{array}$ & $\begin{array}{l}0.018 \\
0.179\end{array}$ & $\begin{array}{l}0.016 \\
0.205\end{array}$ & $\begin{array}{r}-0.019 \\
0.266\end{array}$ & $\begin{array}{l}-0.076 \\
-0.096\end{array}$ & $\begin{array}{r}0.001 \\
-0.026\end{array}$ & $\begin{array}{r}0.001 \\
-0.058\end{array}$ & $\begin{array}{r}0.003 \\
-0.002\end{array}$ & $\begin{array}{l}.061 \\
.029\end{array}$ \\
\hline $\begin{array}{l}\text { New Laws Needed to } \\
\text { Restrict Games }\end{array}$ & $\begin{array}{l}\text { Age } \\
\text { Gender }\end{array}$ & $\begin{array}{l}\text { Direct Game Exp. } \\
\text { Direct Game Exp. }\end{array}$ & $\begin{array}{l}0.013 \\
0.349\end{array}$ & $\begin{array}{l}0.013 \\
0.365\end{array}$ & $\begin{array}{r}-0.018 \\
0.248\end{array}$ & $\begin{array}{l}-0.046 \\
-0.063\end{array}$ & $\begin{array}{r}0.001 \\
-0.016\end{array}$ & $\begin{array}{r}0.001 \\
-0.041\end{array}$ & $\begin{array}{l}0.002 \\
0.001\end{array}$ & $\begin{array}{l}.036 \\
\mathrm{n} / \mathrm{a}\end{array}$ \\
\hline
\end{tabular}

621

633 Note. All coefficients weighted by representativeness of participants across the United States general population. 
Table 6: Observed Variables in Study 3.

\begin{tabular}{|c|c|c|c|c|c|}
\hline & 1. & 2. & 3. & 4. & 5. \\
\hline 1. Age & -- & & & & \\
\hline 2. Gender & .02 & -- & & & \\
\hline 3. Caregiver & $-.19 * * *$ & .00 & -- & & \\
\hline 4. Caregiver Co-Play & -.08 & $-.12 * * *$ & -- & -- & \\
\hline 5. Direct Game Experience & $-.23 * * *$ & $-.10 * * *$ & $.11 * * *$ & $.71 * * *$ & -- \\
\hline
\end{tabular}

638

639 Note: Zero-order correlation coefficients weighted by representativeness of participants across the United Kingdom general 640 population. $* * * p<.001$. 
Table 7: Perceptions of Positive Game Effects.

642

\begin{tabular}{|c|c|c|c|c|c|c|c|c|c|c|c|c|c|c|c|c|c|c|}
\hline & \multicolumn{6}{|c|}{ Empirically Accurate Evaluation } & \multicolumn{6}{|c|}{ Large Effect Estimated } & \multicolumn{6}{|c|}{ No Effect Estimated } \\
\hline & $B$ & $S E$ & LL CI & UL CI & $p$ & $\begin{array}{l}\text { Exp } \\
\text { (B) }\end{array}$ & $B$ & $S E$ & LL CI & UL CI & $p$ & $\begin{array}{l}\text { Exp } \\
\text { (B) }\end{array}$ & $B$ & $S E$ & LL CI & UL CI & $p$ & $\begin{array}{l}\text { Exp } \\
\text { (B) }\end{array}$ \\
\hline \multicolumn{19}{|l|}{ Gender $^{\dagger}$} \\
\hline Men & 0.35 & .126 & 1.11 & 1.81 & .006 & 1.42 & 0.29 & .157 & 0.98 & 1.82 & .066 & 0.99 & -0.20 & .130 & 0.64 & 1.06 & .123 & 1.01 \\
\hline \multicolumn{19}{|l|}{ Caregiver ${ }^{\dagger *}$} \\
\hline Not Caregiver & -0.34 & .153 & 0.53 & 0.96 & .025 & 0.71 & -0.12 & .195 & 0.60 & 1.30 & .529 & 0.88 & 0.05 & .166 & 0.76 & 01.46 & .743 & 1.06 \\
\hline \multicolumn{19}{|l|}{ Caregiver Co-Play $\dagger$} \\
\hline No Co-Play & -1.11 & .282 & 0.19 & 0.57 & $<.001$ & 0.33 & -1.76 & .381 & 0.08 & 0.35 & $<.001$ & 0.17 & 0.26 & .319 & 0.70 & 2.44 & .404 & 1.31 \\
\hline \multicolumn{19}{|l|}{ Direct Game Exp. ${ }^{\dagger \sharp}$} \\
\hline Most days & 0.94 & .188 & 1.77 & 3.70 & $<.001$ & 2.56 & 1.09 & .222 & 1.92 & 4.58 & $<.001$ & 2.97 & -0.07 & .196 & 0.63 & 1.37 & .709 & 0.93 \\
\hline Once a week & 1.28 & .223 & 2.33 & 5.59 & $<.001$ & 3.61 & 1.42 & .258 & 2.50 & 6.87 & $<.001$ & 4.14 & 0.03 & .242 & 0.64 & 1.66 & .899 & 1.03 \\
\hline Once a month & 0.89 & .256 & 1.46 & 3.99 & .001 & 2.41 & 0.56 & .332 & 0.92 & 3.37 & .089 & 1.76 & -0.44 & .295 & 0.36 & 1.15 & .134 & 0.64 \\
\hline Several times a year & 0.56 & .223 & 1.13 & 2.70 & .013 & 1.74 & -0.06 & .323 & 0.50 & 1.77 & .842 & 0.94 & -0.55 & .249 & 0.35 & 0.94 & .026 & 0.57 \\
\hline Once a year & 0.23 & .320 & 0.67 & 2.35 & .477 & 1.26 & -0.15 & .222 & 0.35 & 2.10 & .737 & 0.86 & -0.32 & .325 & 0.38 & 1.37 & .321 & 0.73 \\
\hline
\end{tabular}

Notes. $\uparrow$ Denotes analysis corrects for participant age, $\$$ denotes analysis controls for participant gender. Responses of "I don't know"

645 used as contrast for multinomial logistic models. Coefficients weighted by representativeness of participants across the United

646 Kingdom general population. 
Table 8: Perceptions of Negative Game Effects.

\begin{tabular}{|c|c|c|c|c|c|c|c|c|c|c|c|c|c|c|c|c|c|c|}
\hline & \multicolumn{6}{|c|}{ Empirically Accurate Evaluation } & \multicolumn{6}{|c|}{ Large Effect Estimated } & \multicolumn{6}{|c|}{ No Effect Estimated } \\
\hline & $B$ & $S E$ & LLCI & ULCI & $p$ & $\begin{array}{l}\text { Exp } \\
\text { (B) }\end{array}$ & $B$ & $S E$ & LLCI & ULCI & $p$ & $\begin{array}{l}\text { Exp } \\
\text { (B) }\end{array}$ & $B$ & $S E$ & LL CI & UL CI & $p$ & $\begin{array}{l}\text { Exp } \\
\text { (B) }\end{array}$ \\
\hline Gender $^{\dagger}$ & 0.05 & .119 & 0.83 & 1.32 & .691 & 1.05 & -0.58 & .136 & 0.43 & 0.73 & $<.001$ & 0.56 & 0.78 & .192 & 1.50 & 3.18 & $<.001$ & 2.18 \\
\hline $\begin{array}{l}\text { Caregiver }{ }^{\dagger} \\
\quad \text { Not Caregiver }\end{array}$ & -0.33 & .148 & 0.54 & 0.96 & .027 & 0.72 & -0.07 & .177 & 0.66 & 1.32 & .679 & 0.93 & -0.18 & .219 & 0.54 & 1.28 & .402 & 0.83 \\
\hline $\begin{array}{r}\text { Caregiver Co-Play }{ }^{\dagger \ddagger} \\
\text { No Co-Play }\end{array}$ & -1.02 & .277 & 0.21 & 0.62 & $<.001$ & 0.36 & -0.50 & .326 & 0.32 & 1.15 & .128 & 0.61 & -0.96 & .402 & 0.18 & 0.85 & .017 & 0.38 \\
\hline $\begin{array}{r}\text { Direct Game Exp. }{ }^{\dagger} \\
\text { Most days } \\
\text { Once a week } \\
\text { Once a month } \\
\text { Several times a year } \\
\text { Once a year }\end{array}$ & $\begin{array}{l}0.94 \\
1.20 \\
0.97 \\
0.39 \\
0.31\end{array}$ & $\begin{array}{l}.178 \\
.213 \\
.268 \\
.211 \\
.303\end{array}$ & $\begin{array}{l}1.81 \\
2.18 \\
1.56 \\
0.98 \\
0.76\end{array}$ & $\begin{array}{l}3.63 \\
5.04 \\
4.47 \\
2.23 \\
2.48\end{array}$ & $\begin{array}{l}<.001 \\
<.001 \\
<.001 \\
.066 \\
.302\end{array}$ & $\begin{array}{l}2.56 \\
3.32 \\
2.64 \\
1.47 \\
1.37\end{array}$ & $\begin{array}{r}-0.17 \\
0.39 \\
-0.18 \\
-0.75 \\
-0.15\end{array}$ & $\begin{array}{l}.208 \\
.241 \\
.339 \\
.281 \\
.342\end{array}$ & $\begin{array}{l}0.56 \\
0.92 \\
0.43 \\
0.27 \\
0.44\end{array}$ & $\begin{array}{l}1.26 \\
2.37 \\
1.63 \\
0.81 \\
1.69\end{array}$ & $\begin{array}{l}.405 \\
.104 \\
.607 \\
.007 \\
.670\end{array}$ & $\begin{array}{l}0.84 \\
1.48 \\
0.84 \\
0.47 \\
0.86\end{array}$ & $\begin{array}{r}1.03 \\
0.89 \\
1.27 \\
0.18 \\
-0.84\end{array}$ & $\begin{array}{l}.263 \\
.309 \\
.343 \\
.334 \\
.730\end{array}$ & $\begin{array}{l}1.68 \\
1.33 \\
1.82 \\
0.62 \\
0.10\end{array}$ & $\begin{array}{l}4.70 \\
4.46 \\
6.98 \\
2.30 \\
1.81\end{array}$ & $\begin{array}{l}<.001 \\
.004 \\
<.001 \\
.591 \\
.252\end{array}$ & $\begin{array}{l}2.81 \\
2.43 \\
3.56 \\
1.20 \\
0.43\end{array}$ \\
\hline
\end{tabular}

653

Notes, $\uparrow$ Denotes analysis corrects for participant age, $\ddagger$ denotes analysis controls for participant gender. Coefficients weighted by representativeness of participants across the United Kingdom general population. 
656 Table 9: Study 3 Indirect Effects of Indirect Experience on Empirically Accurate Evaluation of Game Effects.

657

\begin{tabular}{|c|c|c|c|c|c|c|c|c|c|c|}
\hline $\begin{array}{c}\text { Dependent } \\
\text { Variable (DV) }\end{array}$ & $\begin{array}{c}\text { Independent } \\
\text { Variable (IV) }\end{array}$ & $\begin{array}{c}\text { Mediating Variable } \\
(\mathrm{MV})\end{array}$ & $\begin{array}{l}\text { Total Effect } \\
\text { IV to DV }\end{array}$ & $\begin{array}{l}\text { Direct Effect } \\
\text { IV to DV }\end{array}$ & $\begin{array}{l}\text { IV to } \\
\text { MV }\end{array}$ & $\begin{array}{l}\text { MV to } \\
\text { DV }\end{array}$ & $\begin{array}{c}\text { Indirect } \\
\text { Effect }\end{array}$ & \multicolumn{2}{|c|}{$\begin{array}{l}\text { Boot-Strapped Bias Corrected } \\
\text { 95\% C.I. for Indirect Paths }\end{array}$} & $\begin{array}{c}\text { Model } \\
\text { Variance }\end{array}$ \\
\hline $\mathrm{Y}$ & $\mathrm{X}$ & $\mathrm{Z}$ & $\mathrm{c}$ & $\mathrm{c}^{\prime}$ & $\mathrm{a}$ & $\mathrm{b}$ & $a * b$ & Lower Level & Higher Level & $* R^{2}$ \\
\hline \multirow{4}{*}{$\begin{array}{l}\text { Empirically } \\
\text { Accurate } \\
\text { Evaluation of } \\
\text { Positive Influence }\end{array}$} & Age & Direct Game Exp. & -0.017 & -0.013 & -0.028 & 0.159 & -0.004 & -0.006 & -0.003 & .051 \\
\hline & Gender & Direct Game Exp. & -0.112 & -0.054 & -0.336 & 0.176 & -0.059 & -0.102 & -0.028 & .040 \\
\hline & Caregivers & Direct Game Exp. & 0.429 & 0.353 & 0.519 & 0.171 & 0.223 & 0.051 & 0.141 & .046 \\
\hline & $\begin{array}{l}\text { Parent-Child } \\
\text { Co-Play }\end{array}$ & Direct Game Exp. & 0.796 & 0.496 & 2.604 & 0.117 & 0.305 & -0.089 & 0.699 & $\mathrm{n} / \mathrm{a}$ \\
\hline \multirow{4}{*}{$\begin{array}{l}\text { Empirically } \\
\text { Accurate } \\
\text { Evaluation of } \\
\text { Negative Influence }\end{array}$} & Age & Direct Game Exp. & -0.014 & -0.010 & -0.028 & 0.158 & -0.004 & -0.006 & -0.003 & .047 \\
\hline & Gender & Direct Game Exp. & -0.081 & -0.204 & -0.336 & 0.173 & -0.058 & -0.098 & -0.025 & .040 \\
\hline & Caregivers & Direct Game Exp. & 0.464 & 0.389 & 0.519 & 0.166 & 0.086 & 0.046 & 0.139 & .047 \\
\hline & $\begin{array}{l}\text { Parent-Child } \\
\text { Co-Play }\end{array}$ & Direct Game Exp. & 0.397 & -0.208 & 2.604 & 0.233 & 0.606 & 0.231 & 1.043 & .046 \\
\hline
\end{tabular}

658 